\title{
Ascorbate Peroxidase and Superoxide Dismutasegenes Alteration in Tomato (Solanum lycopersicum Mill) under Drought Stress Condition
}

\author{
Gyanendra Kumar Rai ${ }^{1 *}$, Ojesvi Mahajan ${ }^{1}$, Sonalika Kotwal ${ }^{1}$, Muneeba Banoo ${ }^{2}$, \\ Monika Singh ${ }^{3}$, Pradeep Kumar Rai ${ }^{4}$ and B.K. Sinha ${ }^{2}$ \\ ${ }^{1}$ School of Biotechnology, SKUAST-Jammu, J\&K - 180009, India \\ ${ }^{2}$ Division of Plant Physiology, SKUAST-Jammu, J\&K - 180009, India \\ ${ }^{3}$ G.L. Bajaj Institute of Technology and Management, Greater Noida, \\ GB Nagar, UP - 201306, India \\ ${ }^{4}$ ACHR, SKUAST-Jammu, Udheywala, Jammu J\&K - 180002, India \\ *Corresponding author
}

\section{Keywords \\ Tomato, \\ Drought,Ascorbate \\ Peroxidase, \\ Superoxide \\ dismutase, RT-PCR \\ Article Info \\ Accepted: \\ 20 July 2018 \\ Available Online: \\ 10 August 2018}

\section{A B S T R A C T}

Tomato (Solanum lycopersicum Mill), a major horticultural crop belongs to family Solanaceae, consumed all over the world. It is an undetached part of food due to its taste and nutritional value. It is good source of minerals, vitamin and antioxidant characteristics. Climate change produces so many natural hazards such as abiotic and biotic stress in the plant. Drought is a factor which affects morphological, physiological, biochemical and yield attributes of plants due to excess generation of toxic elements such as reactive oxygen species (ROS), create oxidative damage to the cellular organization. In this study under drought stress condition morphological and physiological traits are significantly decreased which compare to normal grown tomato. Maximum reduction was noted in Yield $(60.00 \%)$, number of leaves $(53.17 \%)$, number of fruit /cluster $(37.77 \%)$ and fruit setting $(32.95 \%)$ under drought stress at growth stage. Electrolyte leakage $(21.20 \%)$ showed highest under drought stress condition. Maximum RWC (77.86\%) and specific leaf area $\left(6.43 \mathrm{~cm}^{2} \mathrm{~g}^{-1}\right)$ were noted under control condition. Ascorbate Peroxidase (APX) and Superoxide Dismutase (SOD) gene expression was enhanced under drought stress condition as compare to control. Maximum APX transcript i.e. 2.464 and SOD transcript i.e., 2.988 were recorded in plant which drought stressed at growth stage. Minimum i.e. 1.320 and 1.97 was noted APX and SOD gene, respectively under well watered plant. The relationship between morphological and physiological traits and antioxidant gene expression profile was found to be a very significant indicator of the effects of drought stress in plants.

\section{Introduction}

India is the second largest producer of tomato accounting for $10.58 \%$ of the world's production (FAO, 2011). The production of tomato in India is about 196.97 lakh tonnes in 2017 (Hort. Stat. 2017). According to the fifth assessment report of IPCC (2014), drought is the significant impact of current climate related extremes. In India, drought is a regular 
problem which affects agriculture production and life of animals and humans frequently. Of the total geographical area of India, two third parts receive rainfall less than $1000 \mathrm{~mm}$ which is not distributed equally. According to statistical review, India has only $40 \%$ water use efficiency of total existing irrigation projects. Around $68 \%$ of net sown area (140 million hectare) is affected by drought conditions and $50 \%$ of this area is known as severe region where drought regularly shows its affect (http://www.dsc.nrsc.gov.in). About 3.3\% of total geographical area of Jammu and Kashmir is under cultivation, of which $70 \%$ is rainfed with frequent moisture stress. Tomato crop is more sensitive to moisture paucity and requires abundance of moisture for qualitative yield, at various stage i.e. vegetative, growth, reproductive, flowering and fruit setting (Rao et al., 2000). Moisture stress induced oxidative stress with over production of reactive oxygen species (ROS) e.g. superoxide radicals $\left(\mathrm{O}^{-2}\right)$, hydroxyl radicals $\left(\mathrm{OH}^{-}\right)$and hydrogen peroxides $\left(\mathrm{H}_{2} \mathrm{O}_{2}\right)$, which react with structural and functional organic molecules, including proteins, sugars, lipids and nucleic acids causing disturbance of cellular metabolism (Rai et al., 2018).Various Anti-oxidant enzymes (Super-oxide dismutase, Catalase and Ascorbate peroxidases etc.) have antioxidant properties and considered as the main components of defense machinery under drought stress (Asada, 1992; Rai et al., 2018 and Berwal et al., 2018). Under drought stress, increases in intracellular levels of Reactive Oxygen Species (ROS) were found to cause significant damage to cell structures (Bhattachrjee, 2005) and influence the expression of a numbers of genes such as SOD and GPX and APX expressed under moisture stress condition (Gill and Tuteja, 2010). Drought is one of the most widespread environmental stresses and affects almost all the plant functions. Due to rapidly growing world's population and increased in environmental changes and production of high quality food also increases with reduced inputs and there is an immediate need to solve the problem (Noaman et al., 2004). Keeping in view the relative scarcity of the genotype specific comparative study and the importance of antioxidant defense system in tomato under drought stress condition. Antioxidant enzymes may reveal genetic variability in plant adaptation to moisture stress via alterations in gene expression and/or the post-transcriptional regulation of enzymatic activity. The objective of the current study is to explore the antioxidative responses and compare the expression of antioxidant genes in plants under moisture stress conditions as well as physiological adaptation. Knowledge of antioxidant metabolism could provide valuable information for understanding the drought tolerance related mechanisms in tomato that could potentially lead to better breeding strategies for crop improvement programme.

\section{Materials and Methods}

The pot experiments were conducted at Division of Plant Physiology and laboratory work was done at School of Biotechnology, SKUAST Jammu. Tomato cultivar Pusa Ruby was procured from Division of Vegetable Science and Floriculture, SKUAST Jammu.

\section{Plant growing and drought stress treatment}

The Pusa Ruby cultivar was selected for the experiment, which is recommended and maximum cultivated in vegetable growing area of Jammu and Kashmir. Tomato seeds were disinfested with the Trichoderma viride. Plants were prepared by the sowing the seeds in nursery (last week of January, 2018) in module tray $(10 \leq \mathrm{cm}$ depth) filled with peat moss. After 25 days, tomato plants were transplanted to the 10plastic pots $(30 \mathrm{~cm}$ diameter) field with 1 vermicompost: $2 \mathrm{~S}$ and: 
1 peat (By volume) in and placed in experimental area of Division of Plant Physiology, SKUAST-Jammu. On 25 April, 2018 water stress treatments were initiated when plants had four to five nodes/ plants (25-30 $\mathrm{cm}$ height). Total 10 pots were separated in to two groups (5 each). One group plants received no water till temporary wilting. Second group plants were well watered.

\section{Morphological traits}

Plant height $(\mathrm{cm})$ of all the all plants of each group was measured in centimetres from the base of the plant to tip of the main shoot at the time of final picking and average plant height of each genotype was worked out. Leaves were counted from individual plants. Number of flowers per cluster was counted manually starting from bottom to top in each cluster and on every branch of a plant. Five clusters were tagged in each plants and manually counted flower per cluster. Number of flowers per plant was staring from bottom to top in each cluster and on every branch of a plant. Fruit setting (\%) was calculated by dividing number of fruits per cluster with number of flowers per cluster and then multiplying with 100. Fruits were harvested from tagged flower clusters and weigh the single fruit weight $(\mathrm{g})$.Yield per plant $(\mathrm{kg})$ was noted, manually weigh the fruit weight at every harvesting time till the plant life.

\section{Physiological traits}

\section{Specific leaf area $\left(\mathrm{m}^{2 /} / \mathrm{kg}\right)$}

Specific leaf area (SLA) is defined as the leaf area per unit leaf weight and is expressed as $\mathrm{m}^{2} \mathrm{~kg}^{-1}$. Specific leaf area of leaves was calculated by the formula described by Hunt, R. (1978).

SLA = Leaf area/ Leaf dry weight

\section{Relative water content}

The relative water content (RWC) in the leaves was calculated according to the formula (Barrs and Weatherly, 1962). The leaf dry weight was measured after oven drying at $65^{\circ} \mathrm{C}$ for $36 \mathrm{~h}$, and the saturated weight was measured after incubating the leaves in moist filterpaper for $4 \mathrm{~h}$ in Petri dishes at room temperature.

RWC $(\%)=[($ fresh weight - dry weight $) /$ (saturated weight - dry weight)] x100

\section{Electrolyte leakage}

Total ions leaked out of the leaf were determined by the suggested method of Ben Hamed et al., (2007). Leaf disc were taken in a glass tube containing $20 \mathrm{ml}$ of distilled water and electrical conductivity (EC) was measured $\left(\mathrm{EC}_{1}\right)$. The tubes were heated at $45^{\circ} \mathrm{C}$ for $30 \mathrm{~min}$ in water bath, and electrical conductivity was measured $\left(\mathrm{EC}_{2}\right)$. Later the contents were again boiled at $100^{\circ} \mathrm{C}$ for 10 min, and electrical conductivity was again recorded $\left(\mathrm{EC}_{3}\right)$. The electrolyte leakage was calculated using formula:

Electrolyte leakage $\%=\left(\mathrm{EC}_{2}-\mathrm{EC}_{3} / \mathrm{EC}_{1}\right) 100$

[EC $\mathrm{EC}_{1}$-electrical conductivity of distilled water, $\mathrm{EC}_{2}$-electrical conductivity at $45^{\circ} \mathrm{C}, \mathrm{EC}_{3^{-}}$ electrical conductivity at $100^{\circ} \mathrm{C}$ ]

\section{Gene expression analysis}

After 5 days of drought treatment, leaves were harvested randomly from both treatments i.e. watered and drought stressed plants and frozen in liquid nitrogen and stored at $-80^{\circ} \mathrm{C}$ for future RNA extraction. Frozen samples were ground in a chilled mortar and pestle using liquid nitrogen and RNA extracted using Trizol method (TRIzol ${ }^{\mathrm{TM}}$ Reagent from Invitrogen Catalog Numbers: 15596026, UK). The quality of the isolated 
total RNA was checked on MySPEC(VWR, USA). Two prominent peaks were observed in all the samples with OD 260/280 ratio of $>2.0$. First strand cDNA synthesis was carried out using RevertAid ${ }^{\mathrm{TM}} \mathrm{H}$ minusFirst Strand cDNA synthesis kit (Thermo Fisher Scientific, USA). The cDNA products were diluted 50-fold with deionized water before using it as a template in qRT-PCR. Primer sequences used for gene expression are- APX and SOD, and Actin (constitutively expressed and used as a house keeping gene for normalization) and are given in table 1 . The PCR reaction were carried out in thermal cycler.Quantitative real-time PCR was performed using the StepOne ${ }^{\mathrm{TM}}$ System (ABI, ThermoFisher) as per the protocol mentioned in our earlier publication (Kumar et al., 2017).The quantitative fold changes in mRNA expression were determined relative to actin mRNA levels in each corresponding group and calculated using the $2^{-\mathrm{DDCT}}$ method (Livak and Scmittgen, 2001).

\section{Statistical analysis}

The effect of moisture stress on morphological and physiological changes in tomato and the gene expression pattern of APX and SOD by RT-PCR were checked for statistical significance and represented as a mean \pm according to $t-$ test. This test is used to determine when the values of two samples are significant or non- significant. The standard benchmark of calculating $\mathrm{p}$ - value is $5 \%$ (0.005). When the $\mathrm{p}$ - value is smaller than the significance level we reject the null hypothesis as being false and accept our alternative hypothesis.

\section{Results and Discussion}

\section{Effect of drought stress in morphological changes in tomato}

The data (Table 2) revealed significant decrease in plant height in tomato cultivar under drought stress condition $(\mathrm{p}=0.010)$. The average plant height i.e. $66.00 \pm 0.88 \mathrm{~cm}$ was noted in controlled condition while the average plant height i.e. $48.00 \pm 1.73 \mathrm{~cm}$ was noted under drought stress condition at growth stage. The plant height was decreased by $26.11 \%$ under drought stress condition. The data revealed decrease in number of leaves in tomato under drought stress condition $(\mathrm{p}=0.003)$. The mean value of leaves i.e. $152.33 \pm 10.52$ was noted in controlled condition while $71.33 \pm 7.31$ number of leaves was noted under drought treatment condition at growth stage. The number of leaves was decreased by $53.17 \%$ under drought stress condition. The data revealed decrease in number of flowers/ cluster in tomato cultivar under drought stress condition $(p=0.789)$. The average number of flowers/ cluster i.e.12.66 \pm 0.66 was noted in controlled condition while the average number of leaves i.e. $12.00 \pm 2.08$ was noted under drought stress condition at growth stage.

The number of flowers/ cluster was decreased by $5.21 \%$ under drought stress condition. The data revealed decrease in number of fruits/ cluster in tomato cultivar under drought stress condition $(\mathrm{p}=0.05)$. The average number of fruits/ cluster i.e. $9.00 \pm 0.57$ was noted in controlled condition while the average number of leaves i.e.5.66 \pm 0.88 was noted under drought treatment condition at growth stage. The number of fruits/ cluster was decreased by $37.77 \%$ under drought stress condition. The data revealed decrease in fruit setting percentage in tomato cultivar under drought stress condition $(p=0.003)$. The average value of fruit setting percentage i.e.71.00 \pm 2.43 was noted in controlled condition while the average value of fruit setting percentage i.e. $47.60 \pm 1.2$ was noted under drought treatment condition at growth stage. The value of fruit setting percentage was decreased by $32.95 \%$ under drought stress condition. The data revealed decrease in single fruit weight in tomato cultivar under 
drought stress condition $(\mathrm{p}=0.075)$. The average value of single fruit weight i.e.16.80 \pm 1.76 was noted in controlled condition while the average value of single fruit weight i.e. $11.53 \pm 1.32$ was noted under drought stress. The data revealed decrease in yield/ plant in tomato cultivar under drought stress condition $(\mathrm{p}=0.015)$. The average value of yield/ plant i.e. $2.15 \pm 0.22$ was noted in controlled condition while the average value of yield/ plant i.e.0.86 \pm 0.11 was noted under drought stress condition at growth stage. The value of yield / plant was decreased by $60 \%$ under drought stress conditions.

\section{Effect of drought stress in physiological changes in tomato}

The data revealed decrease in relative water content in tomato cultivar under drought stress condition $(\mathrm{p}=0.035)$. The average value of relative water content i.e.77.86 \pm 1.74 was noted in controlled condition while the average value of relative water content i.e. $61.73 \pm 1.93$ was noted under drought stress condition at growth stage. The value of relative water content was decreased by $17.9 \%$ under drought stress condition. The data showed increase in relative water content in tomato cultivar under drought stress condition $(\mathrm{p}=0.035)$ (Table 3). The mean value of electrolyte leakage i.e.0.896 \pm 0.17 was noted in controlled condition while the mean value of electrolyte leakage i.e. $21.20 \pm 2.51$ was noted under drought stress conditionat growth stage. The value of electrolyte leakage was increased by $136.6 \%$ under drought stress condition (Table
3).Specific leaf area in tomato cultivar under drought stress condition was showed significant variation $(\mathrm{p}=0.070)$ under drought stress condition. Maximum specific leaf area i.e. $6.43 \pm 0.03$ was noted in well watered condition plants while the minimum value of specific leaf area i.e. $3.23 \pm 0.20$ was noted under drought stressed plants at growth stage. The value of specific leaf area was decreased by $49.76 \%$ under drought stress condition (Table 3).

Transcript profiling of antioxidant genes, Ascorbate peroxidase (APX) and Superoxide dismutase (SOD)

Results of the qRT-PCR expression profiling of Ascorbate peroxidase (APX) and Superoxide dismutase (SOD) was carried out in response to well watered and drought stress at growth stage $(25-30 \mathrm{~cm}$ plant height) are depicted in figure 1 . Slight but significant increase in APX transcripts was observed under drought stress condition. The highest expression levels of genes APX and SOD were observed under drought stress condition. Actin was used as a reference gene for the normalization. Maximum APX transcript expression i.e. 2.464 fold was noted under drought stress, while minimum i.e. 1.320 fold expressed in non-stressed plant compare to housekeeping gene. Similarly trends were observed in case of SOD transcript expression. SOD gene transcript level i.e. 2.988 and 1.97 fold with compare to actin gene was noted in drought stressed plants and well watered plants, respectively.

Table.1 Primer oligonucleotide sequence of APX, SOD and Actin

\begin{tabular}{|l|l|l|}
\hline Gene & Forward Primer $\left(\mathbf{5}^{\prime} \rightarrow \mathbf{3}^{\prime}\right)$ & Reverse Primer $\left(\mathbf{5}^{\prime} \rightarrow \mathbf{3}^{\prime}\right)$ \\
\hline APX & TGAGCTCGCCCATGGCGCCAA & ATCTCAACAGCAACAACACCAG \\
\hline SOD & GGCTTGCATACAAACCTGAA & CTGACTGCTTCCCATGACAC \\
\hline Actin & CCGCTCTTGCTCCGAGCAG & ATCCACATCTGTTGGAAGGTAC \\
\hline
\end{tabular}


Table.2 Changes in morphological character and yield and yield attributing traits under drought stress

\begin{tabular}{|l|l|l|l|l|}
\hline Parameters & Controlled & Drought & $\begin{array}{l}\text { \%change under } \\
\text { drought stress }\end{array}$ & $\begin{array}{l}\text { P Value } \\
@ 5 \%\end{array}$ \\
\hline Plant height & $66.00 \pm 0.88$ & $48.00 \pm 1.73$ & -26.11 & 0.010 \\
\hline Number of leaves & $152.33 \pm 10.52$ & $71.33 \pm 7.31$ & -53.17 & 0.003 \\
\hline $\begin{array}{l}\text { Number of } \\
\text { flowers/cluster }\end{array}$ & $12.66 \pm 0.66$ & $12.00 \pm 2.08$ & -5.21 & 0.789 \\
\hline $\begin{array}{l}\text { Number of } \\
\text { fruits/cluster }\end{array}$ & $9.00 \pm 0.57$ & $5.66 \pm 0.88$ & -37.77 & 0.05 \\
\hline Fruit setting (\%) & $71.00 \pm 2.43$ & $47.60 \pm 1.2$ & -32.95 & 0.003 \\
\hline Single fruit weight & $16.80 \pm 1.76$ & $11.53 \pm 1.32$ & -31.54 & 0.075 \\
\hline Yield/Plant & $2.15 \pm 0.22$ & $0.86 \pm 0.11$ & -60 & 0.015 \\
\hline
\end{tabular}

Table.3 Changes in Relative Water Content (RWC), Electrolyte leakage (EL) and Specific Leaf area under drought stress

\begin{tabular}{|l|l|l|l|}
\hline Parameters & $\begin{array}{l}\text { Relative Water } \\
\text { Content }(\%)\end{array}$ & $\begin{array}{c}\text { Electrolyte } \\
\text { leakage(\%) }\end{array}$ & \multicolumn{1}{|c|}{$\begin{array}{c}\text { Specific leaf } \\
\mathrm{area}\left(\mathrm{cm}^{2} \mathrm{~g}^{-1}\right)\end{array}$} \\
\hline Controlled & $77.86 \pm 1.74$ & $08.96 \pm 0.17$ & $6.43 \pm 0.03$ \\
\hline Drought & $61.73 \pm 1.93$ & $21.20 \pm 2.51$ & $3.23 \pm 0.20$ \\
\hline Pvalue@5\% & 0.035 & 0.039 & 0.070 \\
\hline $\begin{array}{l}\text { \%age decrease in drought } \\
\text { stress condition }\end{array}$ & -17.9 & +136.6 & -49.76 \\
\hline
\end{tabular}

Figure.1 Transcript profiling of antioxidant genes in tomato cultivar Pusa Ruby

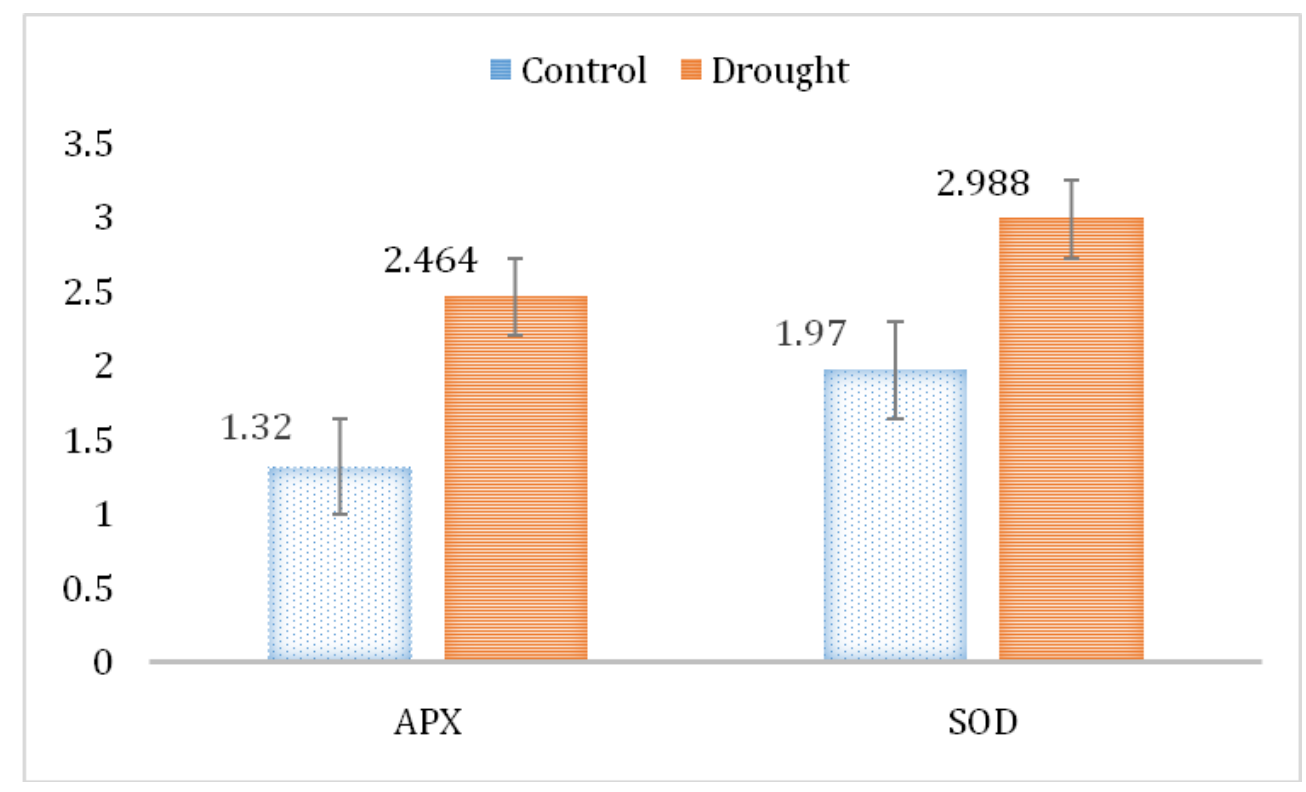


Drought is one of the most widespread environmental stresses and affects almost all the plant functions. To gain insights into the determinants underlying drought tolerance, the present study dealt with the morphological and physiological and molecular analyses in tomato in response to drought. The findings presented in results indicated that drought stress influenced the plant morphological and physiological characters as well as antioxidant defence mechanism. Therefore, an attempt has been made to discuss changes in morphological traits, physiological traits and antioxidant defence machinery in tomato plants.

Plant height is an important agronomic parameter that reflects the vegetative growth performance of crop plants in response to the stressed conditions (Anjum et al., 2016 a; Wang et al., 2016). Earlier studies showed that drought stress is a main limiting factor that suppresses the numerous growth related traits in crop plants. Similar findings was recorded in this study, the plant height was decreased $26.11 \%$ under drought stress condition. The suppression in plant height is primarily ascribed to lessening in the cell expansion and elongation (Manivannan et al., 2007; Jaleel et al., 2009). Similarly findings were also reported by the Specht et al., (2001), Bhatt, Rao (2005) and Khan et al., (2001) in soybean, okra and maize, respectively. The total leaves per plants was noted minimum under drought stress condition. The results agreement with the findings of Anjum et al., (2011) and Reddy et al., (2003). However, Abdelmula and Sabiel (2007) concluded that vegetative attributes (i.e. number of leaves per plant) are not influenced essentially by drought. They argued that this character is exceptionally impacted and controlled by genetic factors as opposed to the environmental factors. The number of leaves per plant is influenced by water stress; diminished longevity and narrowing of individual leaf size are described by reduction in soil water potential (Anjum et al., 2011). Factors responsible for leaf expansion like, maintenance of leaf turgor, accumulation of assimilates and temperature were genuinely modified because of drought stress. Number of flowers/ cluster i.e. $12.66 \pm 0.66$ and $12.00 \pm 2.08$ was noted in controlled and drought stress condition, respectively. The number of flowers/ cluster, number of fruits/ cluster, fruit setting, single fruit weight and yield per plants was decreased under drought stress condition. The results are agreement with the findings of Giardini et al., (1988), under low water condition, tomato plant has reduced yield and fruit size. The reason of yield reduction is nutrient uptake of minerals are also reduces under low soil water condition i.e., nitrogen, sodium, sulphur, potassium, magnesium and calcium (Nahar and Gretzmacher, 2002). Blum (2005) suggested that a small leaf area is helpful under drought stress in order to avoid hydration.

RWC is possibly the most suitable measure of plant water status in terms of the physiological consequence of cellular water deficit. It's express the relative quantity of water extant in the plant tissues. In this research, drought stress significantly reduced RWC from $77.86 \%$ under control condition to $61.73 \%$ under drought stressed plants. The reduction in RWC indicated a loss of turgor that resulted in limited water availability for cell expansion process and subsequently suppressed plant growth development. The results of this study clearly showed the reduction of plant growth characters. Blokhina et al., (2003) by microscopic investigations of dehydrated plant cells revealed the presence of cell membrane cleavage and its increasing permeability under drought stress condition. They mentioned that the concentrations of appropriate solutes that could preserve membrane were not sufficient 
and the plant was not able to adjust osmotically. In fact, highest RWC is a drought tolerance mechanism and due to this is related to osmotic regulation or less elasticity of tissues (Ritchie et. al., 2003). The osmotic adjustment is the process of accumulation of solutes in response to water stress by maintaining turgor in tissues (Jones et. al., 1980 and Ford and Wilson, 1981). A decrease in the relative water content (RWC) in response to drought stress has been noted in wide variety of plants as reported by Nayyar and Gupta (2006). Increase in electrolyte leakage in both the genotypes under water deficit conditions was noted. Under stress conditions, reactive oxygen species (ROS), such as superoxide radicals, singlet oxygen, hydrogen peroxide and hydroxyl radicals are produced in large amounts which can damage proteins, lipids and DNA (Dat et al., 2000). As a result, peroxidation of lipids occurs which disrupts the membrane integrity of the plant cell. This means that essential solutes leak out from the organelles and from the cell and cause the damage of membrane function and metabolic imbalances (Blokhina et al., 2003). Quan et al., (2004) also reported higher electrolyte leakage in drought stressed maize (Zea mays L.) plants than the plants grown under control conditions. A similar increase in electrolyte leakage was described in two different Populus populations subjected to drought stress reported byXiao et al., (2009).

The plant cells have extremely effective antioxidative defense system gets rid of the harmful effect of oxidative stress.Amongst various antioxidant enzymes, superoxide dismutase (SOD) has been found to play most important role in the tolerance mechanism of the plants to the abiotic stresses. Superoxide dismutase, one of the most effective antioxidants in plants, catalyzes the dismutation of superoxide anion radicals into hydrogen peroxide and oxygen, specifically eliminating the ROS and balancing free oxygen radicals (Scandalios, 1993). SOD gene expression patterns at the mRNA level were noted similarly trends like physiological and morphological observations. The current research is the study which has reported and investigated the effect of expression of mRNA levels of SOD genes decreased under controlled condition. Similar findings were also reported in wheat crops under abiotic stress by Kumar et al., (2014) and Deeksha and Rai (2016). Previous research has shown that members of antioxidant gene families are differentially regulated in response to different stresses (Secenji et al., 2010). The expression of $\mathrm{Cyt} \mathrm{Cu} / \mathrm{Zn}$ SODs was observed more in the leaf stalks and young leaves and lowest in the roots (Dong et al., 2011).

L-Ascorbic acid (vitamin C), is the most abundant water-soluble redox compound in plants and eukaryotic algae, plays a multifunctional role in both plants and animals. Ascorbic acid functions as a major cellular antioxidant protecting plant tissues against damage caused by reactive oxygen species (ROS), which are induced by various environmental stresses (Sanmartin et al., 2003; Pavet et al., 2005;. Ascorbic acid also participates in the regulation of many fundamental cellular processes such as photosynthesis, photo-protection, cell cycle, cell expansion, programmed cell death and senescence (Haroldsen et al., 2011). In this study, it has been observed that the APX gene transcripts significantly increased during drought stress conditions in tomato cultivar (Pusa Ruby). Actin was used as a reference gene for the normalization. These results are in accordance with the earlier findings. The steady-state level of the APX cyto transcript in pea and spinach leaves increased in response to high-light illumination, water stress, heat, and methyl viologen treatment (Mittler and Zilinskas, 1992; Yoshimura et al., 2000). 
In conclusion, drought is one of the most widespread environmental stresses and affects almost all the plant functions. To gain insights into the determinants underlying drought tolerance, the present study dealt with the morphological and physiological analysis in tomato in response to drought. The findings presented in this paper indicate that drought stress influenced the plant morphological and physiological characters as well as antioxidant defence mechanism. Therefore, an attempt has been made to discuss changes in morphological traits, physiological traits and antioxidant defence machinery in tomato plants. From the results of this experiment, it can be concluded that higher antioxidant activity in drought stress condition lead to drought stress tolerance mechanism. It can be concluded that stressful conditions led to stress in tomato plants, reflected by decrease in morphological changes and physiological changes except electrolyte leakage. Antioxidative response of tomato plants to drought stress was found to be more vigorous. All these results pointed to the importance of APX gene and SOD gene for stress defence in tomato plants. To overcome the limitations for plant productivity, and to improve crop yields under drought stress, it is important to understand the molecular mechanisms of stress responses in plants. The relationship between morphological and physiological traits and $S O D$ gene expression profile was found to be a very significant indicator of the effects of drought stress in plants. The results also suggest that regulation of the $S O D$ and $A P X$ genes in tomato might occur in more than one step, and the network regulating the APX and SOD pathway might be extremely complex.

\section{References}

Abdelmula A. A., Sabiel S. A. I. (2007). Genotypic and differential responses of growth and yield of some maize (Zea mays L.) genotypes to drought stress. Proceedings of the tropical conference on international agricultural research for development Tropentag 2007. University of Kassel Witzenhausen and University of Göttingen, Germany, 6 p.

Anjum S. A., Ran W., Jian-hang N., Zohaib A., Jin-huan L., Mei-ru L., Ji-xuan S., Jun L., San-gen W., Xue-feng Z. (2016). Exogenous application of ALA regulates growth and physiological characters of Leymus chinensis (Trin.) Tzvel. under low temperature stress. Journal of Animal and Plant Sciences, 26 (5): 1354-1360.

Anjum S. A., Xie X. Y., Wang L. C., Saleem M. F., Man C., Lei W. (2011). Morphological, physiological and biochemical responses of plants to drought stress. African Journal of Agricultural Research, 6 (9): 20262032.

Anjum, F., M.Yaseen, E. Rasul, A. Wahid and S. Anjum (2003). Effect on morphological characters. Pakistan Journal Agric. Sci., 40:43-44.

Anjum, S.A., X. Xie, L. Wang. (2011). Morphological, physiological and biochemical responses of plants to drought stress. African Journal of Agricultural Research,6: 2026-2032.

Asada, K. (1992). Ascorbate Peroxidase-a hydrogen peroxide-scavanging enzyme in plants. Physiologia Plantarum, 85:235-241.

Barrs, H.D. and Weatherley, P.E. (1962). A Re-Examination of the Relative Turgidity Techniques for Estimating Water Deficits in Leaves. Australian Journal of Biological Sciences, 15: 413428.

Ben Hamed K., Castagna, A., Salem E., Ranieri A. and Abdelly C. (2007) Sea fennel (Crithmum maritimum L.) under salinity conditions: a comparison of leaf 
and root antioxidant responses. Plant Growth Regulation, 53 (3): 185-194.

Berwal M. K., Prakash K., Kumar R., Rai Gyanendra Kumar and Hebbar K.B. (2018).Antioxidant Defense System in Plants against Abiotic Stress. In. Rai et al., (2018), Abiotic Stress Tolerance Mechanism: NPH, pp. 175-192.

Bhatt R. M., Rao N. K. S. (2005). Influence of pod load response of okra to water stress. Indian Journal of Plant Physiology, 10 (1): 54-59.

Bhatt, R.M. and N.K. Srinivasa Rao (2005). Influence of pod load response of okra to water stress. Indian J. Plant Physiol., 10: 54.

Bhattachrjee, S. (2005). Reactive oxygen species and oxidative burst: roles in stress, senescence and signal transduction in plant. Current Science, 89: $1113-1121$.

Blokhina O., Virolainen E., and Fagerstedt K. V. (2003). Antioxidants, oxidative damage and oxygen deprivation stress: a review. Annals of Botany, 91:179194.

Blum, A. 2005. Drought resistance, water-use efficiency, and yield potential-are they compatible, dissonant, or mutually exclusive? Australian Journal of Agriculture Research, 56: 1159-1168

Blum, A. (1996). Constitutive traits affecting plant performance under stress.

Dat, J., Vandenbeele, S., Vranova, E., Van Montagu, M., Inze, D. and Van Breusegem, F. (2000). Dual action of the active oxygen species during plant stress responses. Cellular and Molecular Life Sciences, 57: 779-795.

Deeksha and Rai Gyanendra Kumar (2016). Superoxide dismutase and ascorbate peroxidase gene expression analysis in tomato under moisture stress conditions. M.Sc. Thesis, SKUAST-Jammu.

Dong S., Wang Y., Cassidy-Amstutz C., Lu G., Bigler R., Jezyk M.R., Li C., Hall
T.M., Wang Z. (2011). Specific and modular binding code for cytosine recognition in Pumilio/FBF (PUF) RNA-binding domains. Journal of Biol. Chem. 286(30): 26732-42.

FAO (Food and Agriculture Organization) Database 2011.

Ford, C. W. and Wilson, J. R. (1981). Changes in levels of solutes during osmotic adjustment to water stress in leaves of four tropical pasture species. Aust. J. Plant Physiol., 8: 77-91.

Giardini, L., Giovanardi, R. and Borin, M. (1988). Water consumption and yield responses of tomato in relation to water availability at difference soil depth (sic). Acta Horticulturae, 228: 119-126.

Gill, S.S. and Tuteja, N. (2010). Reactive Oxygen Species and Antioxidant Machinery in Abiotic Stress Tolerance in Crop Plants. Plant Physiology and Biochemistry, 48: 909-930.

Haroldsen V.M., Chi-Ham C.L., Kulkarni S., Lorence A., Bennett A.B. (2011). Constitutively expressed DHAR and MDHAR influence fruit, but not foliar ascorbate levels in tomato. Plant Physiology and Biochemistry, 49: 1244-1249.

Horticultural Statistics at a Glance (2017). Horticulture Statistics Division Department of Agriculture, Cooperation \& Farmers Welfare Ministry of Agriculture \& Farmers Welfare Government of India.

Hunt R. (1978) Plant Growth Analysis. Edward Arnold, London, 37.

Intergovernmental Panel on Climate Change (IPCC) Fifth Assessment Synthesis Report-2014.

Jaleel C. A., Manivannan P., Wahid A., Farooq M., Somasundaram R., Panneerselvam R. (2009). Drought stress in plants: a review on morphological characteristics and pigments composition. International 
Journal of Agriculture and Biology, 11 (1): 100-105.

Jones, M. M., Osmond, C. B. and Turner, N. C. (1980). Accumulation of solutes in leaves of sorghum and sunflower in response to water deficits. Aust. J. Plant Physiol., 7: 193-205.

Khan M. B., Hussain N., Iqbal M. 2001. Effect of water stress on growth and yield components of maize variety YHS 202. Journal of Research Science, 12: $15-18$.

Kumar R.R., Goswami S., Shamim M., Mishra U., Jain M., Singh K., Singh J.P., Dubey K., Singh S., Rai Gyanendra K., Singh G. P., Pathak H., Chinnusamy V. and Shelly P. (2017). Biochemical Defense Response: Characterizing the Plasticity of Source and Sink in Spring Wheat under Terminal Heat Stress. Frontiers in Plant Science. doi: 10.3389/fpls.2017.01603.

Kumar R.R., Sharma S.K., Rai GK, Singh K., Choudhary M., Dhawan G., Singh G.P. Goswami S. Pathak H. and Rai R.D. (2014). Exogenous application of putrecine at pre anthesis enhances the thermotolerance of wheat (Triticum aestibvum L). Indian Journal of Biochemistry and Biophysics, 51: 396406.

Livak, K.J., Scmittgen, T.D., (2001). Analysis of relative gene expression data using real-time quantitative PCR and the $2\left({ }^{\wedge} \mathrm{DDC}(\mathrm{T})\right)$ method. Methods 25: 402-408.

Manivannan P., Jaleel C. A., Sankar B., Kishorekumar A., Somasundaram R., Lakshmanan G. A., Panneerselvam R. (2007). Growth, biochemical modifications and proline metabolism in Helianthus annuus L. as induced by drought stress. Colloids and Surface B: Biointerfaces, 59 (2): 141-149.

Mittler, R. and Zilinskas, B.A. (1992). Molecular cloning and characterization of a gene encoding pea cytosolic ascorbate perixidase. J. Biol. Chem., 267: 21802-21807.

Nahar, K., and R. Gretzmacher (2002). Effect of water stress on nutrient uptake, yield and quality of tomato (Lycopersicon esculentum Mill.) under subtropical condition. Die Bodenkultur 53(1): 4551.

Nayyar, H. and Gupta, D. (2006). Differential sensitivity of $\mathrm{C} 3$ and $\mathrm{C} 4$ plants to water deficit stress: association with oxidative stress and antioxidants. Environmental and Experimental Botany, 58: 106-113.

Noaman S.H., Lamis D.S., El-Sayed, A.H., Eman, E.S. (2004). In vitro selection for water stress tolerant callus line of Helianthus annus L. Cv. Myak. Int. J. Agric. Biol. 6: 13-18.

Quan, R., Shang, M., Zhang, H., Zhao, Y. and Zhang, J. (2004). Engineering of enhanced glycine betaine synthesis improves drought tolerance in maize. Plant Biotechnology Journal, 2: 477486.

Rai A., Rai Gyanendra Kumar and Dubey R. S. (2018). Heat Stress and its Effects on Plant Growth and Metabolism. In. Rai et al., (2018), Abiotic Stress Tolerance Mechanism: NPH, pp. 203-235.

Rai Gyanendra Kumar, Bagati S., Rai P. K., Shanti V. R., Bhadwal D., KumarR.R, Singh M. and Singh P.(2018). Reactive Oxygen Species Generation, Antioxidants and Regulating Genes in Crops under Abiotic Stress Conditions. In. Rai et al., (2018), Abiotic Stress Tolerance Mechanism: NPH, pp. 143162.

Rao, N. K. S., Bhatt R. M. and Sadasivan A. T. (2000). Tolerance to water stress in tomato cultivars. Photosynthetica 38(3): 465-467.

Reddy T. Y., Reddy V. R., Anbumozhi V. (2003). Physiological responses of groundnut (Arachis hypogea L.) to 
drought stress and its amelioration: a critical review. Plant Growth Regulation, 41 (1): 75-88.

Ritchie, S.W., Nguyan, H.T.and Holaday. A.S. (1990). Leaf Water content and gas exchange parameters of two wheat genotypes differing in drought resistance. Crop sci., 30: 105-111.

Scandalios, J.G. (1993). Oxygen stress and superoxide dismutases. Plant Physiology, 101: 7-12.

Secenji M., Lendvai C., Miskolczi P, Kocsy G, Galle C., Szucs A. Hoffmann B, Sarvari E., Schweizer P, Stein N, Dudits D, Gyorgyey J. (2010). Differences in root functions during long-term drought adaptation: comparison of active gene sets of two wheat genotypes. Plant Biol., 12: 871-884.

Senaratna T., Merritt D., Dixon K., Bunn E., Touchell D., Sivasithamparam K. (2003).Benzoic acid may act as the functional group in salicylic acid and derivatives in the induction of multiple stress tolerance in plants.Plant Growth Regulation, 39: 77-81.
Specht J. E., Chase K., Macrander M., Graef G. L., Chung J., Markwell J. P., Germann M., Orf J. H., Lark K. G. (2001). Soybean response to water. Crop Science, 41 (2): 493-509.

Wang R., Anjum S. A., Niu J., Liu M., Li J., Zohaib A., Song J., Lv J., Wang S., Zong X. (2016). Exogenous application of brassinolide ameliorate chilling stress in Leymus chinensis (Trin.) Tzvel. by modulating morphological, physiological and biochemical traits. Bangladesh Journal of Botany, 45 (1): 143-150

Xiao, X., Yang, F., Zhang, S., Korpelainen, H. and Li, C. (2009). Physiological and proteomic responses of two contrasting Populus cathayana populations to drought stress. Physiologia Plantarum, 136: $150-168$.

Yoshimura, K., Yabuta, Y., Ishikawa, T. And Shigeoka, S. (2000). Expression of spinach ascorbate peroxidise isoenzymes in response to oxidative stresses. Plant Physiology, 123: 223234.

\section{How to cite this article:}

Gyanendra Kumar Rai, Ojesvi Mahajan, Sonalika Kotwal, Muneeba Banoo, Monika Singh, Pradeep Kumar Rai and Sinha, B.K. 2018. Ascorbate Peroxidase and Superoxide Dismutasegenes Alteration in Tomato (Solanum lycopersicum Mill) under Drought Stress Condition. Int.J.Curr.Microbiol.App.Sci. 7(08): 3670-3681. doi: https://doi.org/10.20546/ijcmas.2018.708.372 